\title{
Some Properties of Compressed Rice Straw
}

\author{
Zabady, F.E; Shetawy, M.A. El Said; El Bessoumy, R.R.; Badr, M.M. \\ Faculty of Agricultural Engineering, Al-azhar University, Nasr City, Cairo, Egypt \\ Corresponding author: rizkjune74@yahoo.com
}

\begin{abstract}
Rice straw was investigated as a raw material for manufacturing a composite for using as a building material. Commercial urea formaldehyde "UF" adhesive was used as a binder in manufacturing process. Different formation pressures "FP" of (5.7, 12.4 and 18.5 MPa) and different percentages of urea formaldehyde "UF" of $(20-40 \%)$ were used in the manufacturing products. Some properties of water absorption percentage "WA" (\%), thickness swelling "TS" (mm) and Acoustic insulation percentage "AI" (\%) were measured and analyzed for the produced composite. The properties of the produced composite were dependent on formation pressures "FP" $(\mathrm{MPa})$ and binding materials percentages "UF" (\%). The results show that the lowest values of "WA" and "TS" were $110.6(\%)$ and $4.85(\mathrm{~mm})$ at "FP" of $18.51(\mathrm{MPa})$ and "UF" of $4 \mathrm{o}(\%)$ after immersion time of $5 \mathrm{~min}$., respectively while the highest value of "AI" was $9.66(\%)$ at "FP" of $5.68(\mathrm{MPa})$ and "UF" of $20(\%)$. Three prediction equations were developed for the previous properties respectively.
\end{abstract}

Key words: Rice straw, adhesive, composite, properties, compressed

\section{Introduction}

Revolution in the agricultural sector has resulted in substantial increases in the quantities of agricultural by-products and wastes of different types. In addition to reed, straw, corn cob and stalk, many other non-traditional materials, such as coir fiber, bagasse, coconut pith, ground nut husk and jute sticks, are obtained as agro-wastes. Utilization of these agro-wastes, apart from solving the problem of their disposal would improve the agricultural economy considerably.

Assoc. Prof. and head of Water and Farm Irri. Sys. Eng. Dept., Fac. of Agric. Eng., Al-Azhar Univ., Nasr City, Cairo, Egypt.

Assoc. Prof. and head of Ag. Structures and environmental control Dept., Fac. of Agric. Eng., AlAzhar Univ., Nasr City, Cairo, Egypt.

Lecturer of Ag. Structures and environmental control Dept., Fac. of Agric. Eng., Al-Azhar Univ., Nasr City, Cairo, Egypt.

Lecturer of Ag. Products Process Dept., Fac of Agric. Eng., Al-Azhar Univ., Nasr City, Cairo, Egypt.

One of the most abandoned materials in Egypt is cellulous non-wood fibrous materials, such as rice straw. The total annual Egyptian crop residues are about $30 \mathrm{Tg}$ (teragram), about 3-4 $\mathrm{Tg}$ of which is rice straw (MSEA, 2007). In fact, rice straw is so abandoned that the Egyptian government allowed straw burning at agricultural fields. In the fall of 1999, an autumnal black cloud appeared above several Egyptian cities, with a thick bitter-smelling fog, due to the straw burning (Kazragis, 2005). Halvarsson (2010) Said that the annual plant materials (e.g., straw) are natural composite lignocellulosic materials. They consist mainly of cellulose, hemicelluloses and lignin. They include also considerable amount of inorganic components (e.g., silica, potassium, phosphorous and sodium). The ash content is in the range of 4-20\% and most of it consists of silica $\left(\mathrm{SiO}_{2}\right)$. The rice straw structure and other annual plants are less homogeneous than the perennial softwoods or hardwoods in the morphological structure. The rice straw is composed of the stem and leaves. The stem is divided into nodes and internodes. The internodes are separated by the nodes at which the leaves are attached. The straw internodes are the optimal straw material for the fiberboards and paper producing industries. The amounts of fiber cell elements are less in nodes and leaves and useless as a fiber raw material after the thermo-mechanical defiberation process. El-Kassas and Mourad (2013) mentioned that the burning, organic composite or land filling is common practices in Egypt. The rice straw is inedible secondary waste material from annual plant and is not used as efficiently as it could be. In the production of bioenergy the high silica and ash composition of rice straw is a major disadvantage as they build up and require special care and extra costs. They complicate the burning technique and handling of such large amounts of ash. The most important benefits of selecting the rice straw (which is agricultural residue and grown in large areas of the world) material for medium density fiberboard (MDF) production are reduction of open field burning of an annual plant and to capture carbon dioxide $\left(\mathrm{CO}_{2}\right)$. In addition, the straw based MDF panels can be recycled or converted to energy after utilization. Kennedy and Wanek (2002) reported that the straw is available at a cheap price wherever grain is grown and stacked like giant bricks to form a thick wall, bales offer super insulation from the heat or cold or noise outside. El-Kassas and Mourad (2013) indicate that the bonding agents are those conventionally employed in forming composite 
products and include both acidic and alkaline type binders. Typical bonding agents are amino resins, phenolic resins, resorcinol resins, tannin resins, isocyanate adhesives or mixtures thereof. Resins which can be used to bond treated straw fibers include urea-formaldehyde resins (UF, melamine urea-formaldehyde resins (MUF), phenolformaldehyde (PF), resorcinol- formaldehyde (RF), tannin formaldehyde (TF), polymeric isocyanate (PMDI) and mixture thereof. The resins can be added in different amounts based on several parameters. Hai-Ian et al., (2006) have studied the effect of a modified Urea-formaldehyde resin on the rice-straw medium density fiberboard that is prepared using the conventional method. Yasin et al., (2010) have conduct a study to review the literature on methods to improve the bondability of straw with conventional resins and to help in efficient utilizing wheat and rice straw as an alternate resource for the industrial manufacture of particleboards and fiberboards. Halvarsson et al., (2008) have investigated wheat straw as a raw material for manufacturing of MDF. Commercial urea melamine formaldehyde (UMF) and a mixture of UMF-resin and urea melamine phenol formaldehyde (UMPF) adhesives were used as binders. They have produced wheat straw-based MDF panels using a resin content varied between 14 and $17(\%)$ at average densities ranged from 750 to $1025\left(\mathrm{~kg} / \mathrm{m}^{3}\right)$ and final thicknesses of approximately 9 and $16 \mathrm{~mm}$. There results showed that, SMDF panels produced with densities above $780 \mathrm{~kg} / \mathrm{m}^{3}$ and resin contents above $14 \%$ met the requirements for wood-based MDF standard. They have used the water treatment, heating and chemical additives in the fiber preparation process and also commercial melaminemodified urea formaldehyde (UMF) resin was used as a binder.

Jones (2001) mentioned that the straw bale walls are super-isolative acoustically; there were two recording studios in the USA built of straw bales for their sound proofing quality and insulation. Straw bale wall systems have also been used near airport runways and motorways in the USA and Europe as sound barriers. Kennedy and Wanek (2002) said that the straw bales offer super insulation from the noise outside. Jones (2001) explained that the straw does not wick (Suck) water into itself like concrete does. It simply gets wet as far as the force of the wind can drive the rain into it. When the rain stops, the natural movement of air or wind around the bales dries them out. This cycle of wetting and drying does not damage the bale. The aim of this study is to decrease the burning of rice straw, also to know the possibility of using it as building material or in building materials manufacturing.

\section{Materials and Methods}

\subsection{Raw Materials:}

Straw of rice "Sakha 101" was harvested from 2013/2014 season. The average length for this variety was about $900 \mathrm{~mm}$. The rice straw was chosen in the present work because of the huge amounts of it that found in Egypt. These amounts are about 3-4 Tg /year (MSEA, 2007). The desired size of rice straw used in the present study was obtained by using two machines; the first one was a cutting forage machine and the second was a grinding residues machine. The desired size of rice straw was obtained by putting a lot of rice straw in the cutting forage machine. The output chops were put in the second machine which has a screen of $2 \mathrm{~mm}$. The commercial urea-formaldehyde resin was supplied by Mansoura for Resins and Chemical Industries, Egypt, Nutrition.

\subsection{A Pressing Apparatus:}

The hydraulic press was used in manufacturing the composite. The press upon the samples was achieved manually by a manual pump and simple acting cylinder with manually return. Model (pm); Press max. (20 Mg); Production Year (1996); Gauge (0- $60 \mathrm{MPa})$; accuracy (2 MPa), The hydraulic press made by SICMI sa.s., Trecasali (Parma), Italy.

\subsection{Pressing Cylinder:}

The samples were compressed in a cylindrical shape to satisfy the requirements of the other measurements. A cylinder was used to compress samples inside it, which was constructed, by ElBessoumy, 2005 from mild steel. The inner and outer diameters were 105.4 and $110 \mathrm{~mm}$, respectively. The thickness and length were 5 and $210 \mathrm{~mm}$, respectively. The cylinder was divided into two longitudinal halves to ease release the sample without any deformation. The two longitudinal halves of the cylinder were joined by two steel rings. In order to press the sample inside the compression cylinder, two disks from steel were used. The diameter of the disk was $104.5 \mathrm{~mm}(0.5 \mathrm{~mm}$ less than compression cylinder diameter) to decrease the friction between disks and the cylinder inner surface. A circular hollow was done in one side of the upper disk with diameter equal the diameter of the pressing apparatus cross-head. This circular hollow has a depth of $2 \mathrm{~mm}$ and in the center of disk surface to insure that the pressure always directed to the cylinder axis. The upper and lower disks thicknesses were done to be $32.5 \mathrm{~mm}$ and $30.5 \mathrm{~mm}$, respectively. The samples obtained from the cylinder after compression was formed to a disk shape with diameter of $104.5 \mathrm{~mm}$ and the thickness differs according to the treatments.

\subsection{Digital Sound Level Meter:}

To study the effect of using commercial ureaformaldehyde resin " $U F$ " formation pressure " $F P$ " and ground rice straw (S)on acoustic insulation percentage "AI" $(\%)$, the sound level meter was used 
to measure the level of sound by decibel " $\mathrm{dB}$ " the specifications of digital sound level meter are as follow (according to manufactured catalogue): Model No. 33-2055a, country: China, Range: $50 \mathrm{~dB}$ to 126 $\mathrm{dB}$, Accuracy: $\pm 2 \mathrm{~dB}$ at $114 \mathrm{~dB}$ SPL, Reference: 0 $\mathrm{dB}=0.0002$ Micro Bar.

\subsection{Cubic Foam:}

Cubic foam was used with digital sound level meter to measure the acoustic insulation of samples without any effect of surroundings sounds meter. Its dimensions were of $300 \times 190 \times 190 \mathrm{~mm}$ and made from foam. It made with a hollow shape from inside to satisfy the compressed samples. The first side diameter was $118 \mathrm{~mm}$ (side of sound source) and the other side was $100 \mathrm{~mm}$ (side of sound level meter microphone). This side was locked with a foam disk with a microphone in its center to insure that the samples are stick in the middle distance of cubic foam.

\subsection{Test Procedures}

The experiments were carried out at the research center of Agricultural Engineering Faculty, Al-Azhar University, Nasr city, Cairo, Egypt. Rice straw is one of agricultural residues that used in the present work, in order to study water absorption percentage "WA" (\%), thickness swelling "TS" and acoustic insulation percentage "AI" (\%) as affected by the following variables: Binding materials percentage "UF" $(\%)$ and Formation pressure " $F P^{\prime}$ at constant holding time of $15 \mathrm{~min}$.

\subsubsection{Binding Material Percentage (\%):}

Three percentages of commercial Urea formaldehyde (UF) resin, as a binding material, were added to ground rice straw residue. The ratio were 20,30 and $40(\%)$ by weight.

2.6.2. Formation Pressure Levels (MPa):

Three formation pressures of 5.7, 12.4 and 18.5

"MPa" were used as a low, medium and high pressure.

\subsubsection{Sample Adjustment For Pressing:}

Every sample had a constant weight of $25 \mathrm{~g}$. The mass of samples were measured by a digital electronic balance with accuracy of $0.01 \mathrm{~g}$ for a mass of $5 \mathrm{~kg}$, the sample was put inside the compression cylinder and compressed between two disks by hydraulic pressing at a selected loading level for a constant hold time of $15 \mathrm{~min}$. The sample was released from the cylinder at the end of pressing and thickness of sample was recorded too. Finally, every sample was put into plastic bags to conserve the moisture content. The samples stored inside a wooden container for a period of two weeks because, the thickness will not change at that time.

\subsection{An Experimental Design:}

The combination of one shape of grounded rice straw and three levels of Formation pressures " $F P$ " $(\mathrm{MPa})$ results in three treatments. These treatments experimented at three ratios of binding materials percentages "UF" $(\%)$ resulting 9 treatments. Each treatment was repeated three times to give three replicates resulting 27 samples.

2.8. Measurements:

The following measurements were made for samples after two weeks:

\subsubsection{Water Absorption Percentage "WA" (\%):}

The number one enemy for the produced composite which fabricated from agricultural residues is water absorption, so this test is the most important tests for it. The initial mass for every sample was recorded, every sample was placed on a narrow wiry mesh and immersed in fresh, clean water at $293-295 \mathrm{~K}\left(20-23^{\circ} \mathrm{C}\right)$ for duration of 5,10 , 15 and 20 (min). Each sample at the end of each period is withdrawn from water and the excess water was strained, then the sample was weighed again, every sample was soaked again to another period of 5 min the same measurements were executed and recorded and so on until $20 \mathrm{~min}$. In the end of twenty minutes the water absorption percentage "WA" was calculated as follows:

$$
" W A "(\%)=\frac{M_{w}-M_{d}}{M_{d}} \times 100
$$

Where:

$M_{w} \quad$ : Mass of wet sample (g). and

$M_{d} \quad$ : Initial mass of sample $(\mathrm{g})$.

2.8.2. Thickness Swelling "TS" (mm):

The samples of the produced composite were immersed vertically in the water for 5, 10, 15 and 20 min to determine the thickness swelling "TS" (mm).

2.8.3. Acoustic Insulation Percentage "AI" (\%):

To determine the acoustic insulation percentage " $A I$ " $(\%)$, the value of sound source was recorded first by a digital sound level and it was $88 \mathrm{~dB}$. The composite sample was put in the middle distance inside cubic foam. The value of sound behind the composite sample was recorded. By subtraction $88 \mathrm{~dB}$ from the reading, after the sample was placed, the resultant was divided by $88 \mathrm{~dB}$ (decibel). The resultant was multiplied by 100 to give the acoustic insulation percentage "AI" $\%$ and so on for all composite samples.

\section{Results and Discussion}

3.1. Water absorption "WA" (\%) of compressed rice straw as affected by binding material percentage "UF" (\%), formation pressure "FP" (MPa) and immersion time "t" (min.):

Figs. (1), (2) and (3) show the relationship between water absorption percentage "WA" (\%) and immersion times " $t$ " $(5,10,15$ and $20 \mathrm{~min})$ at different binding material percentages "UF" $(20,30$ 
and $40 \%)$ and formation pressures " $F P "(5.68,12.37$ and $18.51 \mathrm{MPa}$ ). It is clear that the all curves have the same trends for all experiments. " $A W$ " increases with increasing immersion time " $t$ " while it decreases with increasing " $U F "$ "and " $F P$ ". At " $F P$ " of $5.7 \mathrm{MPa}$, "WA" ranged between (266.83 to $284.58 \%$ ), (193.11 to $206.40 \%$ ) and (139.57 to $149.53 \%$ ) at "UF" of 20,30 and $40 \%$ respectively as in figure (1). While at "FP" of $12.4 \mathrm{MPa}$, "WA" ranged between (209.88 to $230.68 \%),(162.22$ to $141.45 \%)$ and (117.40 to $129.39 \%)$ at " $U F "$ of 20,30 and $40 \%$ respectively as in figure (2). Also, at " $F P "$ of $18.5 \mathrm{MPa}$, "WA" ranged between (192.70 to $214.71 \%)$, (113.44 to $130.66 \%)$ and (110.60 to $125.88 \%$ ) at " $U F "$ of 20 , 30 and $40(\%)$ respectively as in figure (3). The lower value of "WA" was $110.60(\%)$ at "UF" $40 \%$ and " $F P$ " $18.5 \mathrm{MPa}$ after immersion time of $5 \mathrm{~min}$.

-Water absorption percentage "WA" (\%) model of compressed rice straw:

It is clear that the relationship between "WA" and immersion time " $t$ " when binding material "UF" varied satisfied a power function of the form:

$$
W A(\%)=a t^{b}
$$

Fig (4) shows that the best fit relations of the parameter "a" as affected by "UF" at the three different " $F P$ " were power function of the form:

$$
a=c(U F)^{d}
$$

(3)

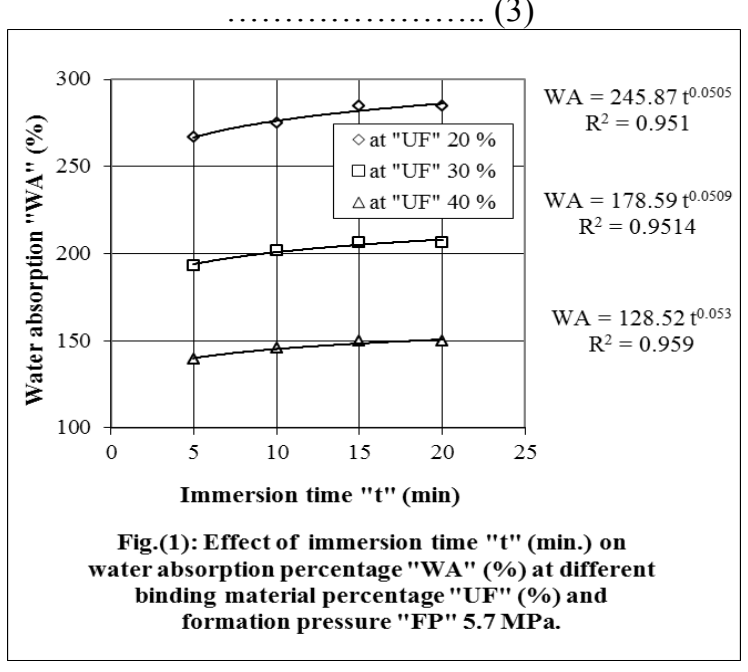

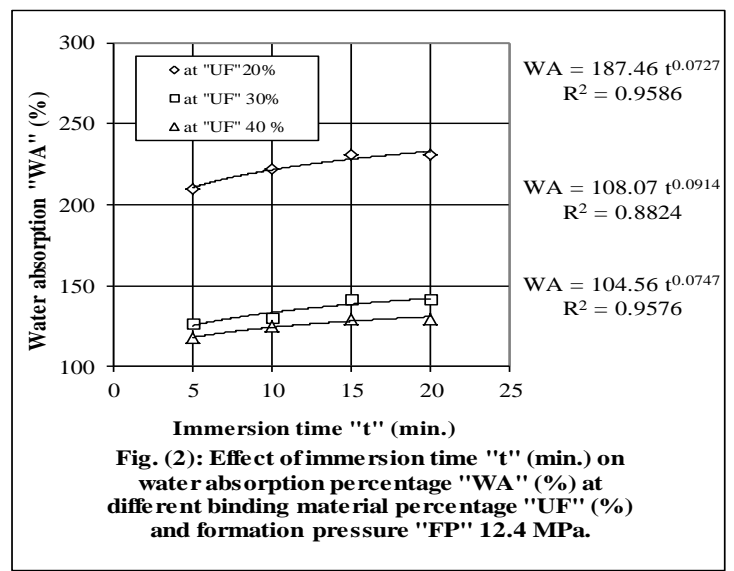
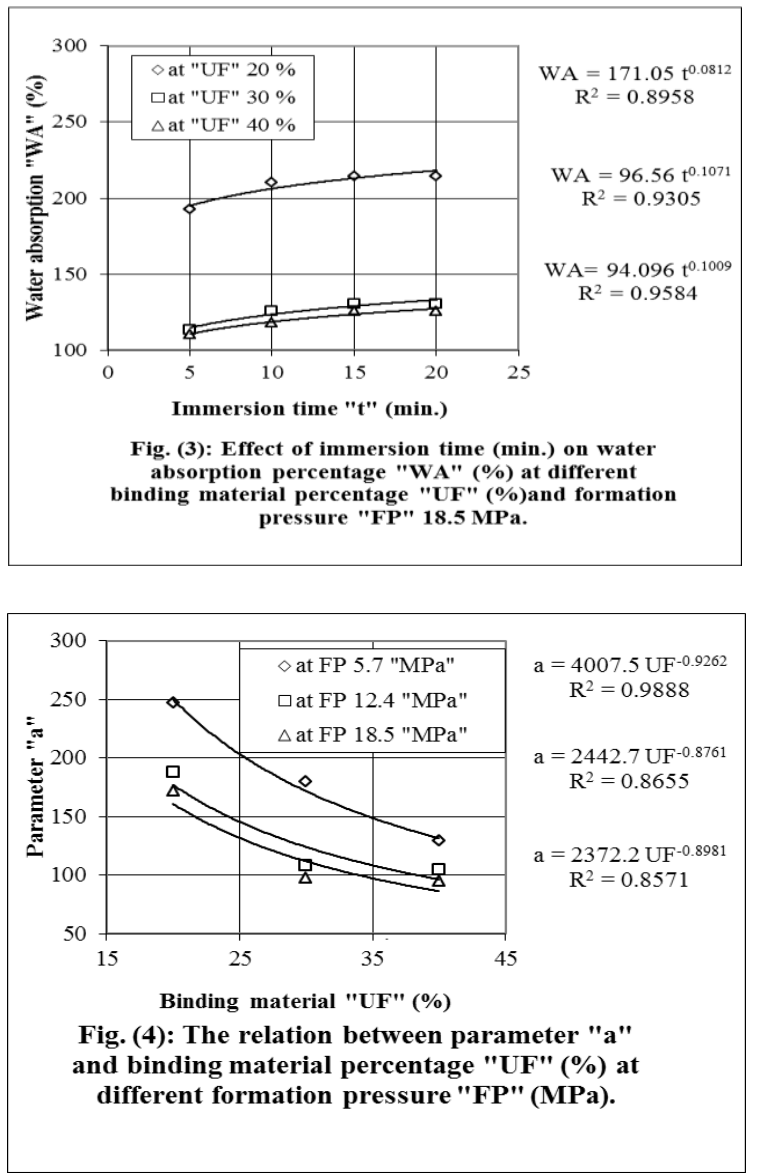


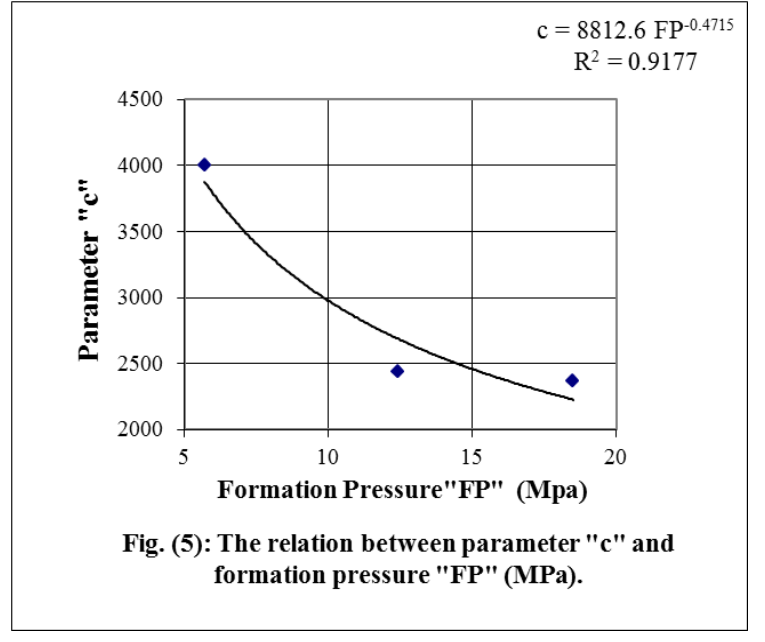

it is clear that the parameter " $b$ " is taken as an average value of 0.1 . The parameter " $c$ " depends on " $F P$ ", the power function was satisfied when the parameter " $c$ " is draw with " $F P$ " as in fig (5).

It is clear that the parameter " $d "$ does not change and it takes value of (-0.9) approximately. The complete prediction empirical equation regarding the collected data of this study for "WA" $(\%)$ is:

$W A(\%)=\left(\left(8812.6 F P^{-0.4715}\right) U F^{-0.9}\right) t^{0.1}$

Fig. (6) Shows the predicted and observed water absorption percentage "WA" (\%).

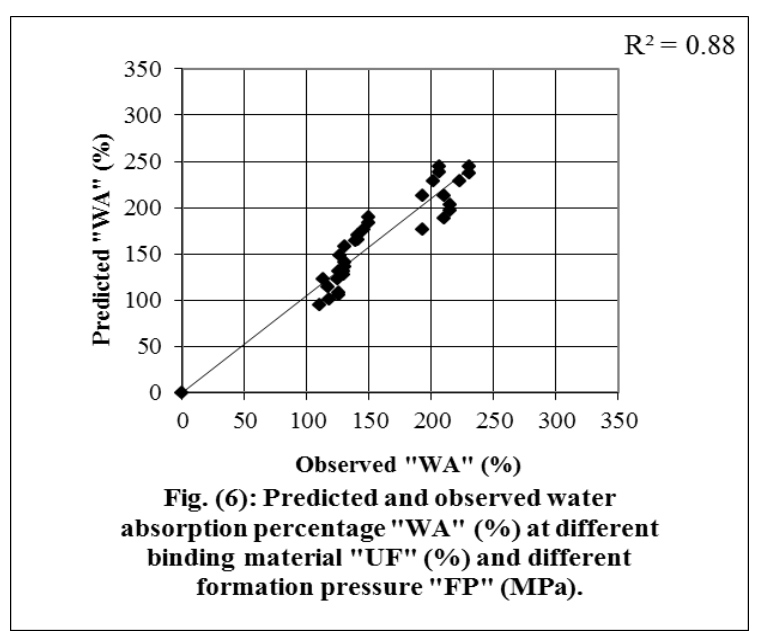

3.2. Thickness swelling "TS" (mm) of compressed rice straw as affected by binding material percentage "UF" (\%)formation pressure "FP" (Map) and immersion time " $\mathrm{t}$ " (min.):

Figs. (7), (8) and (9) show the relationship between thickness swelling "TS" (mm) and immersion time " $t$ " $(5,10,15$ and $20 \mathrm{~min})$ at different binding material percentages " $U F^{\prime \prime}(20,30$ and $40 \%)$ and formation pressures " $F P$ " $(5.68,12.37$ and 18.51 $\mathrm{MPa})$. It is clear that the all curves have the same trends for all experiments. "TS" increases with increasing immersion time " $t$ " while it decreases with increasing "UF" and "FP". At "FP" of $5.7 \mathrm{MPa}$, "TS" ranged between $(9.90-10.50 \mathrm{~mm}, 7.85-8.45 \mathrm{~mm}$ and $7.00-7.60 \mathrm{~mm}$ ) at "UF" of 20,30 and $40 \%$, respectively as in figure (7). While at " $F P$ " of 12.4 $\mathrm{MPa}$, "TS" ranged from (7.77 - $8.60 \mathrm{~mm}, 5.87-6.58$ $\mathrm{mm}$ and $5.56-6.28 \mathrm{~mm}$ ) at "UF" of 20,30 and $40 \%$, respectively as in figure (8). Also, At " $F P "$ of 18.5 $\mathrm{MPa}, " T S "$ ranged from $(6.70-7.5 \mathrm{~mm}, 5.50$ $6.21 \mathrm{~mm}$ and $4.85-5.56 \mathrm{~mm}$ ) at "UF" of 20,30 and $40 \%$, respectively as in figure (9). The lowest value of "TS" was $4.85(\mathrm{~mm})$ at "UF" $40 \%$ and "FP" 18.5 $\mathrm{MPa}$ after immersion time of $5 \mathrm{~min}$.
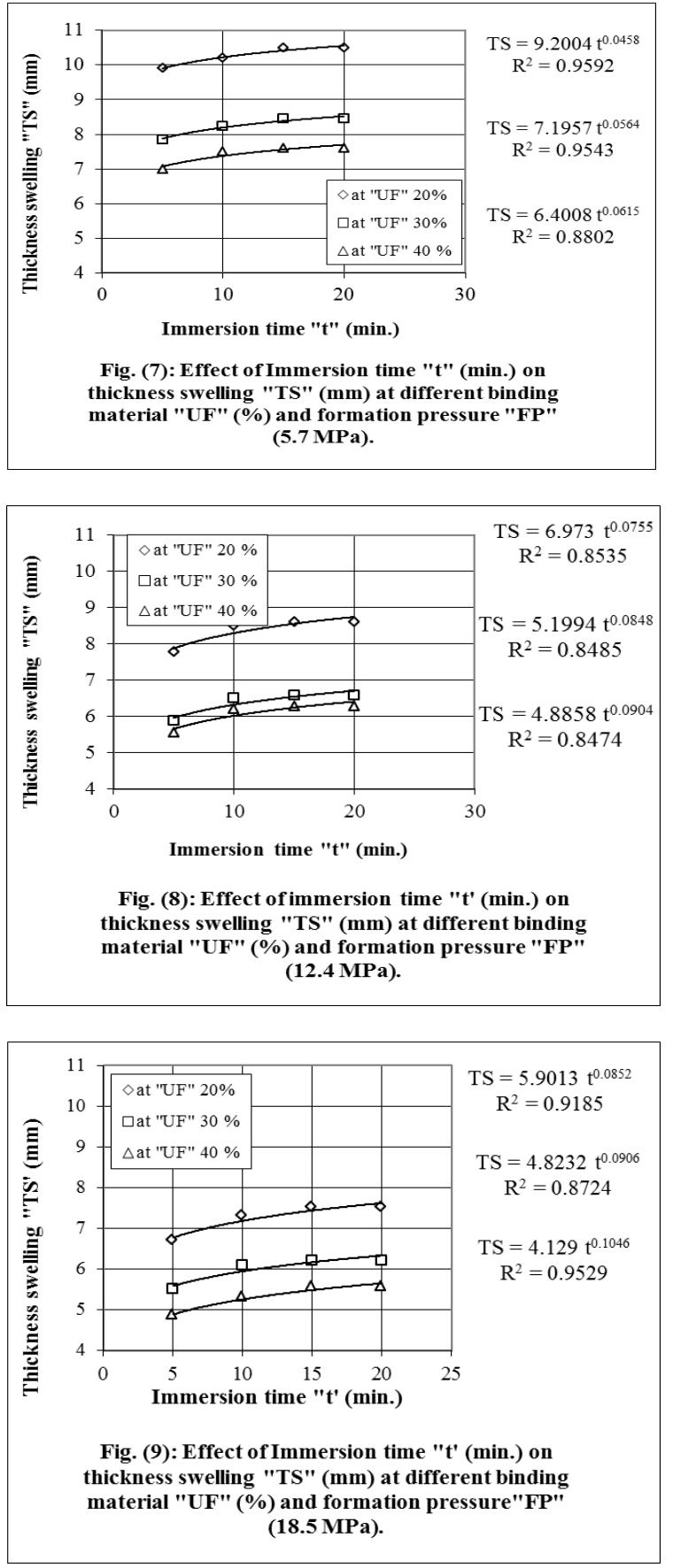
-Thickness swelling "TS" (mm) model of compressed rice straw:

It is clear that the relationship between "TS" and immersion time " $t$ " when binding material " $U F "$ varied satisfied a power function of the form:

$$
T S(m m)=a_{1} t^{b_{1}}
$$

Figs (10) and (11) show that the best fit relations of the parameter " $a_{1}$ " and " $b_{1}$ " as affected by "UF" at the three different "FP" were power function of the form:

$$
a_{1}=c_{1}(U F)^{d_{1}}
$$

$$
b_{1}=k(U F)^{n}
$$
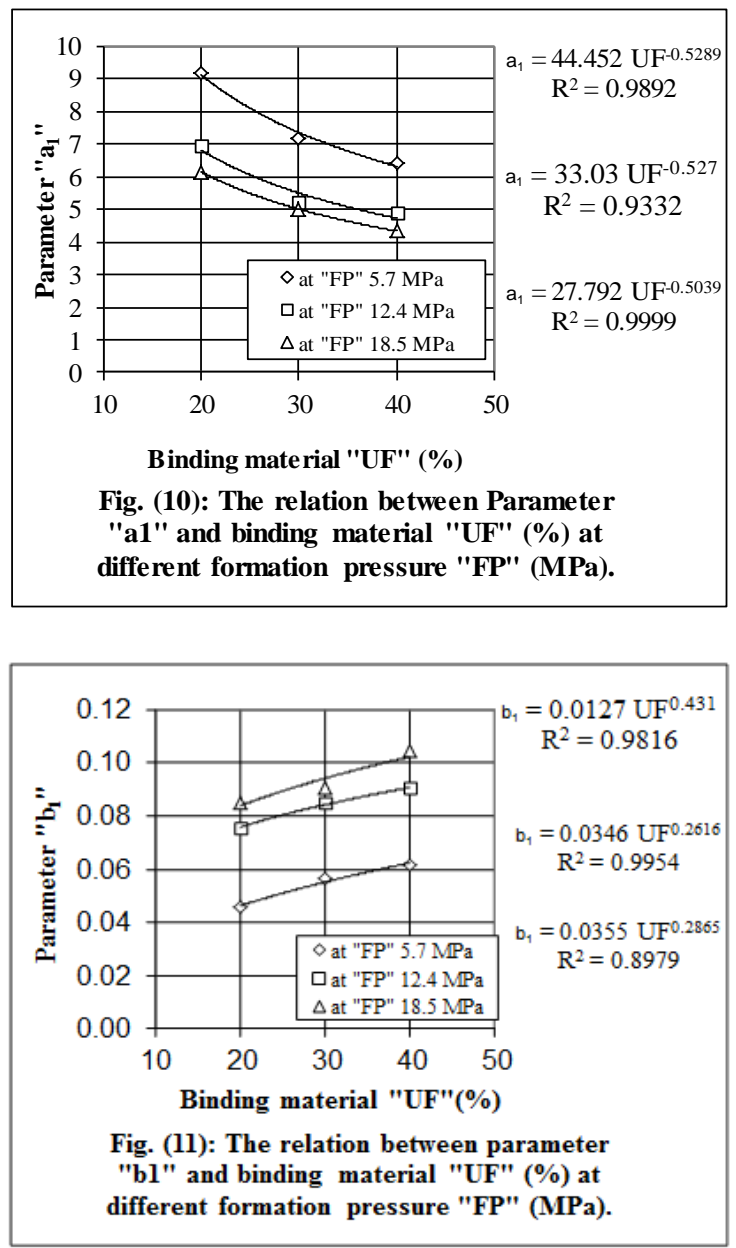

The parameters " $c_{l}$ " and " $k$ " depend on " $F P$ ", the power functions were satisfied when the parameters " $c_{1}$ " and " $k$ " are drawn versus " $F P "$ as in figs (12) and (13).
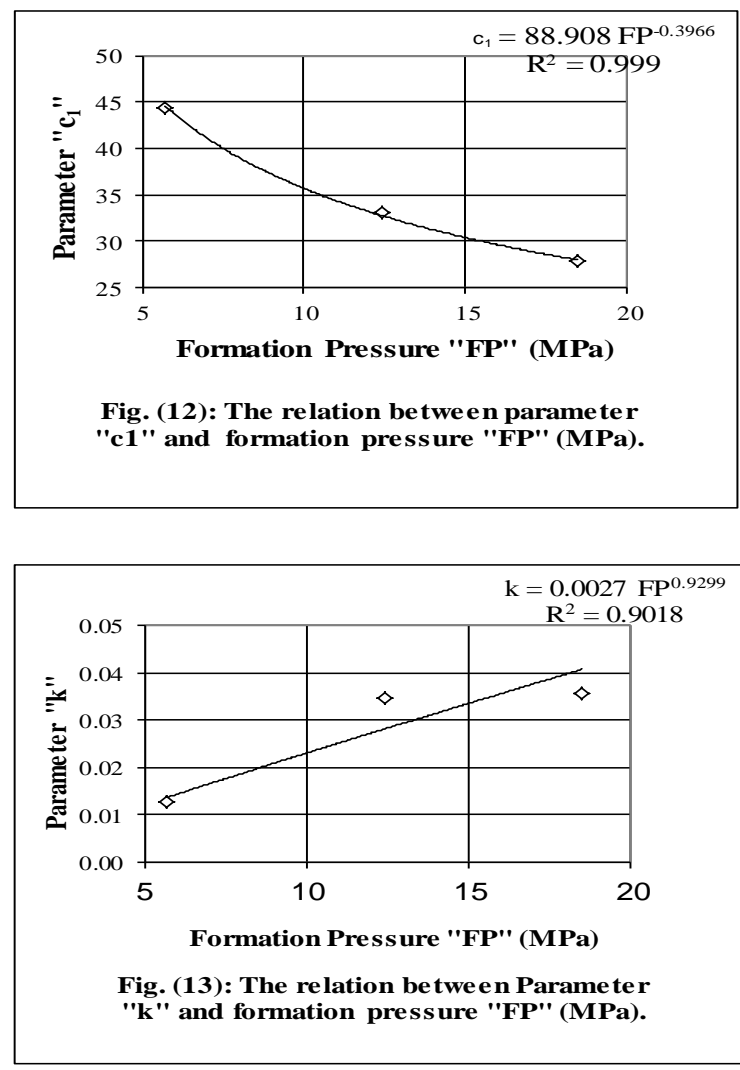

It is clear that the parameter " $d_{l} "$ and " $n "$ does not change and it takes approximately values of 0.520 and 0.326 respectively. The complete prediction empirical equation regarding the collected data of this study for "TS" $(\%)$ is:

$$
\begin{aligned}
& T S(m m)=\left(\left(88.908 F P^{-0.3966}\right)(U F)^{0.520}\right) \\
& \left(t^{\left(0.0027 F P^{0.929}\right)\left(U F^{0.326}\right)}\right)
\end{aligned}
$$

Fig. (14) Shows the predicted and observed thickness swelling "TS" (mm).

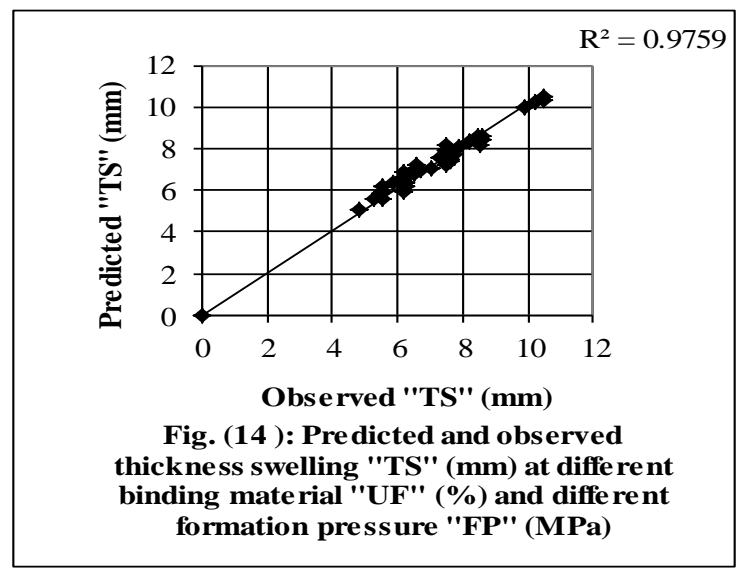

3.3. Acoustic insulation percentage " $A I$ " (\%): 
Fig. (15) Shows the relationship between acoustic insulation percentage "AI" (\%) and binding material percentage " $U F "(\%)$ at different formation pressures " $F P$ " of (5.68, 12.37 and $18.51 \mathrm{MPa})$. "AI" (\%) decreases with increasing "UF" $(\%)$ and "FP". The values of "AI" ranged between (9.66 to $6.81 \%$ ), (8.07 to $6.38 \%)$ and $(7.09$ to $5.75 \%)$ at " $F P "$ of (5.68, 12.37 and $18.51 \mathrm{MPa})$ respectively. The heights value of "AI" was $9.66(\%)$ at "UF" $20(\%)$ and " $F P$ " $5.68 \mathrm{MPa}$.

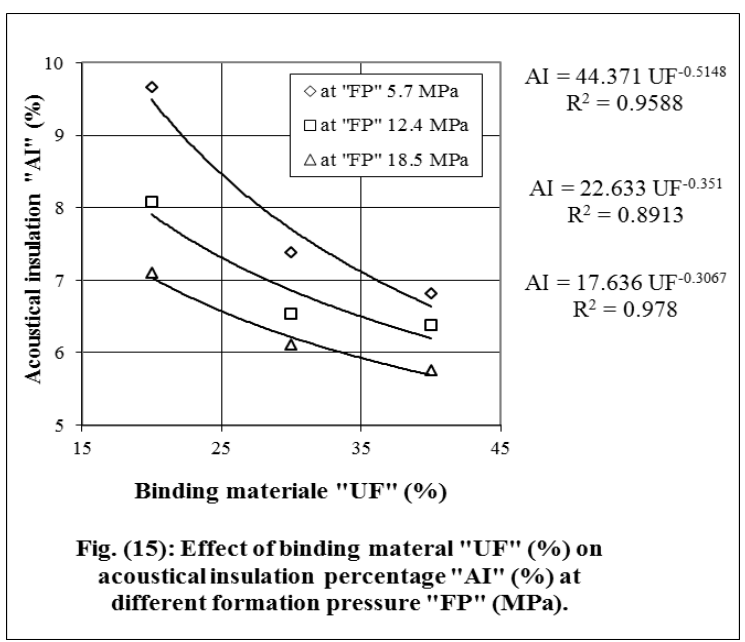

-Acoustic insulation percentage " $A I$ " (\%) model:

Data indicates that the relationship between " $A I$ " and "UF" when formation pressure " $F P$ " varied satisfied a power function of the form:

$$
A I(\%)=a_{2} U F^{b_{2}}
$$

The parameters " $a_{2}$ " and " $b_{2}$ " depend on " $F P$ ", the power function was satisfied when the parameters " $a_{2} "$ and " $b_{2} "$ are drawn with " $F P "$ as in fig (16 and 17).

The complete prediction empirical equation regarding the collected data of this study for "AI" (\%) is:

$$
A I(\%)=\left(174.52 F P^{(-0.7949)}\right)\left(U F^{(1.111 F P}\right.
$$
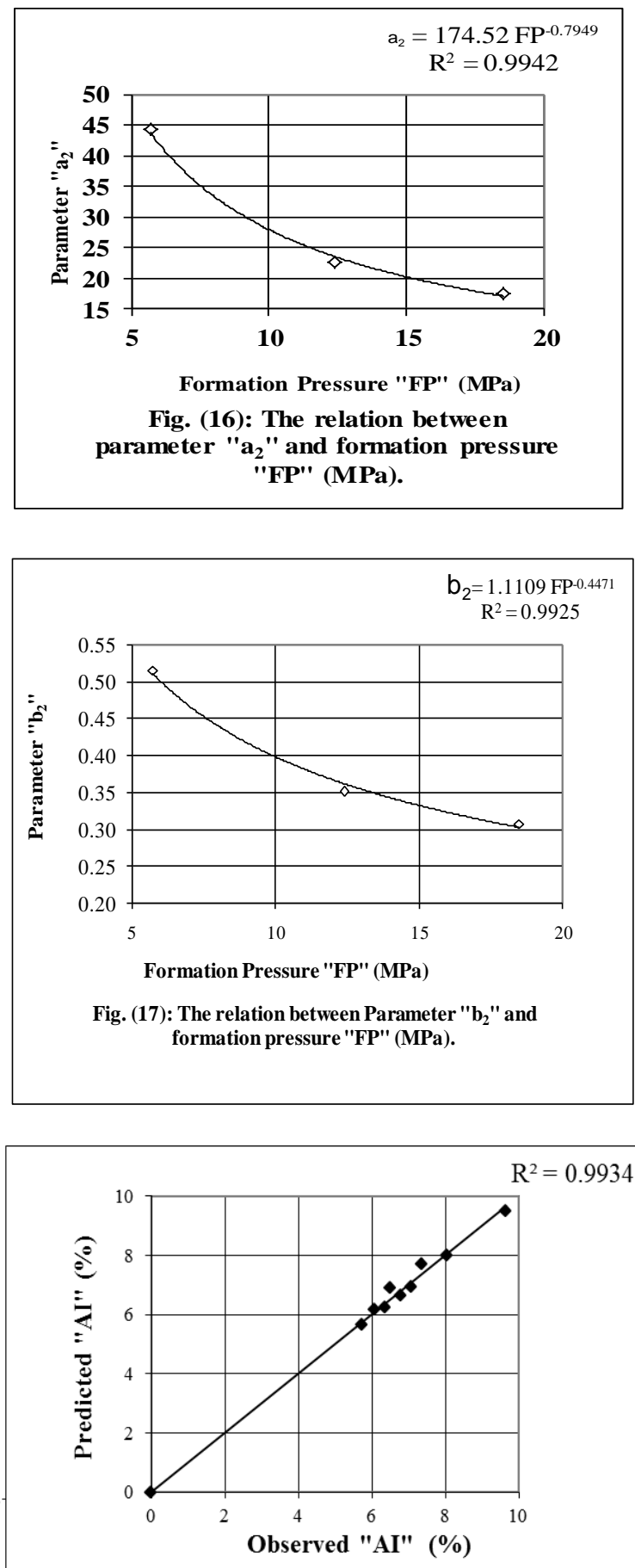

Fig. (18):Predicted and observed acoustical insulation " $\mathrm{AI}$ " (\%) at different binding material "UF" (\%) and different formation pressure "FP" (MPa).

Fig. (18) shows the predicted and observed acoustic insulation percentage "AI" $(\%)$ :

\section{Conclusion}

The produced composite was manufactured from grounded rice straw and urea-formaldehyde " $U F$ " resin as a binding material, the experiments of composite were carried out at the workshop of 
agricultural engineering faculty, Al-Azhar University during year of 2015. The water absorption percentage "WA" (\%), thickness swelling "TS" (mm) and acoustic insulation percentage "AI" (\%) of the produced composite affected by different binding material percentages "UF" ( 20, 30, and $40 \%)$, different levels of formation pressure $(5.7,12.4$ and $18.5 \mathrm{MPa})$ and immersion time of $(5,10,15$ and 20 min) were determined.

The results indicated the following:

The water absorption percentage "WA" (\%) increased with increasing immersion time "mm" and decreased with increasing binding material percentages " $U F$ " and formation pressure " $F P$ " (MPa), The lowest value of "WA" (110.60\%) was obtained at "UF" $40 \%$ and "FP" $18.5 \mathrm{MPa}$ after immersion time of $5 \mathrm{~min}$. A complete water

$$
\begin{gathered}
\text { absorption percentage "WA" (\%) model was: } \\
W A(\%)=\left(\left(8812.6 \mathrm{FP}^{-0.4715}\right) U F^{-0.9}\right) t^{0.1} \\
\mathrm{R}^{2}=0.88
\end{gathered}
$$

The thickness swelling "TS" (mm) increased with increasing immersion time "mm" and it decreased with increasing binding material percentages " $U F "$ and formation pressure " $F P "(\mathrm{MPa})$, The lowest value of "TS" (4.85 mm) at "UF" $40 \%$ and " $F P$ " 18.5 $\mathrm{MPa}$ after immersion time of $5 \mathrm{~min}$. A complete thickness swelling "TS" (mm) model was:

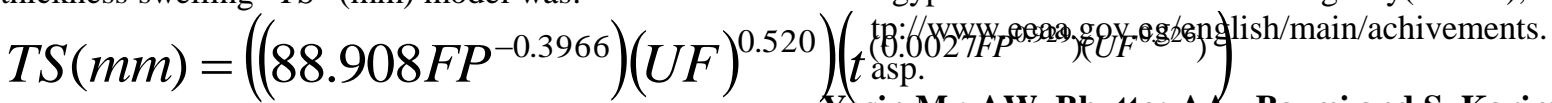

Yasin M.; AW. Bhutto; AA . Bazmi and S. Karim,

$$
\mathrm{R}^{2}=0.98
$$

3-The acoustic insulation percentage "AI" (\%) decreased with increasing binding material percentages " $U F "$ and formation pressure " $F P^{\prime}$ (MPa), the highest value of "AI" (9.66\%) at "UF" 20 $\%$ and " $F P$ " 5.7 MPa. A complete acoustic insulation percentage "AI" (\%) model was:

$$
A I(\%)=\left(174.52 F P^{(-0.7949)}\right)\left(U F^{\left(1.111 F P^{-0.45}\right.}\right)
$$

4- The previous predication equations will be useful for the next studies.

\section{Referances}

EL-Bessoumy, R.R.,(2005). Effect of using agricultural residues in building materials characteristics, MSc., Thesis, Ag. Eng. Dept., Faculty of Agriculture, Al-Zahra University.

El-Kassas, M. A. and A-H.I. Mourad, (2013). Novel fibers preparation technique for manufacturing of rice straw based fiberboards and their characterization, Materials and Design, 50:757-765.
Hai-Ian L.; Y. Ji-xue; and Z. Ding-guo, (2006). Study on modified urea-formaldehyde resin for rice-straw medium density fiberboard. Chem Ind Forest Prod, 26(4):926.

Halvarsson S., (2010). Manufacture of straw MDF and fiberboards, Ph.D Thesis, Department of Natural Sciences, Engineering, Engineering and Mathematics, Mid Sweden University, 92.

Halvarsson S.; H. Edlund, and M. Norgren, (2008). Properties of medium-density fibreboard (MDF) based on wheat straw and melamine modified urea formaldehyde (UMF) resin. Ind Crops Prod, 28(1):37-46.

Jones, B. (2001). Information Guide to strawbale building,

Amazon Nails,Hollinroydfarm,Todmordeu,ol148J,www.st rawbalefutures. org.UK.

Kazragis, A.,(2005). Minimization of atmosphere pollution by utilizing cellulose waste, Journal of Environmental Engineering and Landscape Management, 13(2): 81-90

Kennedy, J.F. and C. Wanek, (2002). The Art of natural building, everybody loves straw bale, new society publishers, Canda, : 291.

MSEA (Ministry of State for Environmental Affairs) (2007). Solid wastes recycling, Egyptian state of environment report, EgyptianEnvironmentalAffairsAgency(EEAA),ht (2010). Efficient utilization of rice-wheat straw to produce value-added composite products, Int $\mathbf{J}$ Chem Environ Eng, 1:136-43. 


\section{بعض خواص قش الارز المضغوط}

د/ فتحى ابراهيم زبادى ، د/ محمد أحمد شتيوى ، د/ رزق ربيع كامل البسومى ، د/ محمد محمد بدر

تم تصنيع مكون من مفروم قش الارز و اليوريا فورمالدهيد كمادة لاحمة لمعرفة مدى إمكانية استخدامها كمادة بناء، وتم إجر اء الإختبار ات فى كلية

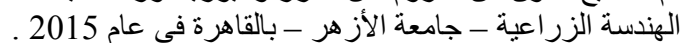

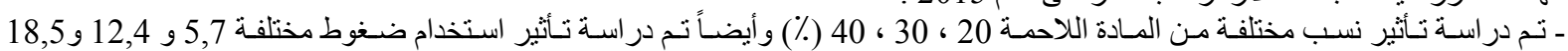
(ميجابسكال) مع زمن كبس ثنابت 15 دقيقة. ـ ت تم قياس الخو اصع الأتية للمنتج:

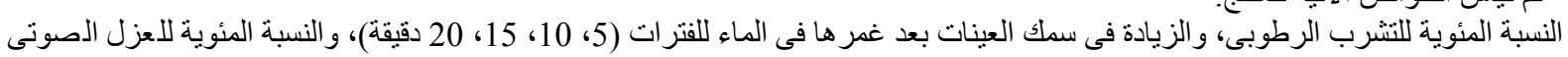

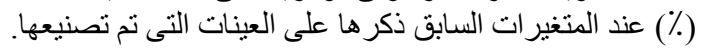

و أظهرت النتائج مايلى:

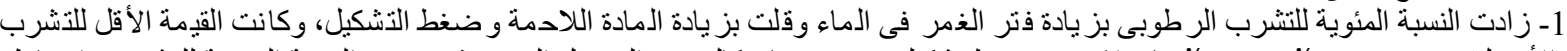

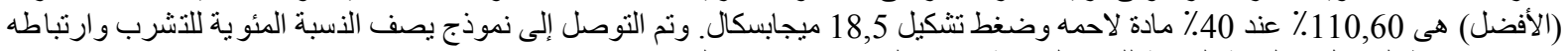
بكلا من ضغط التثكيل و النسبة المئوية للمادة اللاحمة وزمن الغمر، حيث حقق الصورة:

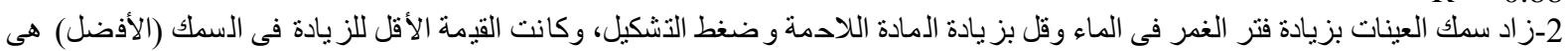

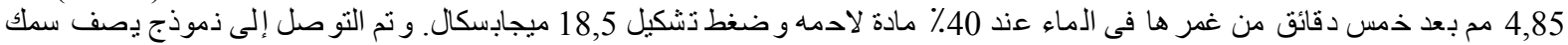

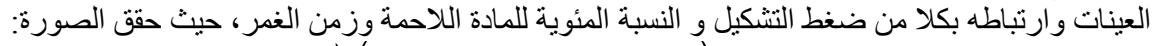
$T S(m m)=\left(\left(88.908 F P^{-0.3966}\right)(U F)^{0.520}\right)\left(t^{\left(0.0027 F P^{0.929}\right)\left(U F^{0.326}\right)}\right)$

\section{$\mathrm{R}^{2}=0.98$}

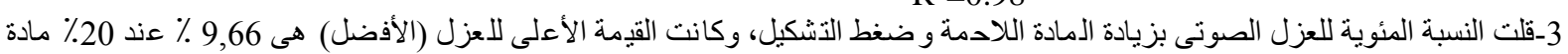

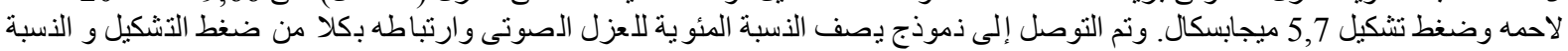
$A I(\%)=\left(174.52 F P^{(-0.7949)}\right)\left(U F^{\left(1.111 F P^{-0.45}\right.}\right)$ المئوية للمادة اللاحمة، حيث حقق الصورة:

$\mathrm{R}^{2}=0.99$

استاذ ورئيس قسم هندسة الرى والصرف المزرعى المساعد بكلية الهندسة الزراعية - جامعة الازهر ـ مدينة نصر - القاهرة.

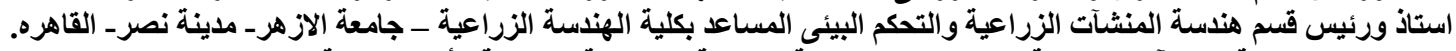

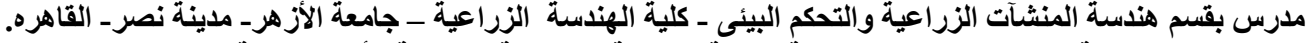
مدرس بقسم هندسة تصنيع المنتجات الزراعية ـ كلية الهندسة الزية الزية الزية - جامعة الأزهر - مدينة نصر - القاهره. 